\title{
Cross Gender Oral Communication from Biological Difference and Socialized Identity to Mutual Understanding
}

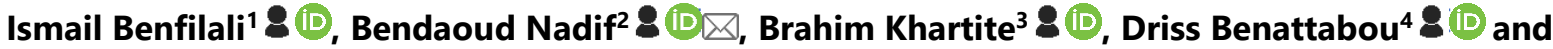 \\ Abdelouahed Bouih $\mathbf{5}$ (iD \\ ${ }^{7}$ Assistant Professor, English Department, Sidi Mohamed Ben Abdellah University, Fez, Morocco \\ ${ }^{2 \& 5} \mathrm{Ph}$ D. Candidate, English Department, Moulay Ismail University, Meknes, Morocco \\ ${ }^{3}$ Professor of ESP \& Business English ENSAM, Moulay Ismail University, Meknes, Morocco \\ ${ }^{4}$ Full Professor, English Department, Moulay Ismail University, Meknes, Morocco Assistant
}

$\triangle$ Corresponding Author: Bendaoud Nadif, E-mail: bendaoudnadif@gmail.com

\section{ARTICLE INFORMATION ABSTRACT}

Received: April 16, 2021

Accepted: May 04, 2021

Volume: 3

Issue: 5

DOI: 10.32996/jweep.2021.3.5.2

\section{KEYWORDS}

Cross- gender communication, computer-mediated communication, dominance, gender difference, gender identity
Language is an indispensable instrument whereby we organize and build our social ties in our communities, and society at large. Human language is critically interwoven into the processes whereby human beings communicate, build knowledge, transmit information, and determine the identity of both the addresser and the addressee in any communicational exchange. We could hypothetically assert that if there is unmistakably one thing without which man as a species can hardly live in the social realm, it is language par excellence. In an admittedly multi-layered and inherently complex sociolinguistic configuration, the individual speaker's linguistic choice, the different roles he or she plays, be they in a position of addresser or addressee, and the various situations where the speech takes place do serve as markers reflecting one's identity and communication styles. In this respect, factors such as sex, age, level of education, occupation, race, and geographical origin can virtually be reflected via one's speech. This article sets out to analyze (1) the influential role of speech, (2) gender and identity, (3) dominance/difference, and (4) cross-gender oral communication in the Moroccan context using a homogenous convenience sample of Moroccan participants. This study falls within the scope of gender studies. Its major aim is to demonstrate the roles that mixed-gendered interlocutors can play in order to maintain effective communication. Therefore, their perceptions regarding interruptions, conversation dominance, turn-taking and choice of topics in conversations are analyzed. Different research instruments have been implemented to collect data including recordings of real-life conversational speech, classroom observation, and interviews. The findings indicate that gender-based differences permeate the conversational styles of both men and women across cultures and with divergent degrees of strength and expression. It has also been shown that although communication breakdown is a source of frustration, it remains a common phenomenon in social interactions. Therefore, overcoming difficulties in maintaining effective communication between members of different genders is dependent on the interlocutors' belief that accepting difference in language and communication styles can make cross-gender communication a satisfactory social experience. This study is expected to raise awareness regarding the socialization processes the two sex groups have gone through which shape in substantial ways the way they speak, behave and interact among each other.

\section{Introduction}

Speech is a human product that has other fundamental functions apart from serving merely as a means of communication. By way of example, if you know a given person's name, it does not necessarily mean that you know that person in any reliable or

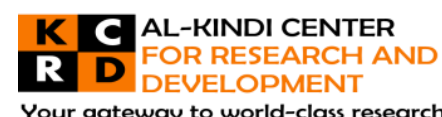

Your gateway to world-class research

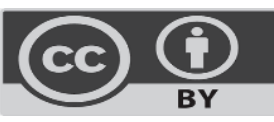

Published by Al-Kindi Center for Research and Development. Copyright (c) the author(s). This open access article is distributed under a Creative Commons Attribution (CC-BY) 4.0 license 
comparably comprehensive way. However, if you converse with that person, you may have other previously inaccessible information made readily available to you, and hence, better identification of him/her. In this case, speech turns out to be a means of identification, a means of getting information on one's interlocutor. Williams and Burden (1997) seem to capture the essence of the problem contending that "language, after all, belongs to a person's whole social being; it is a part of one's identity, and is used to convey this identity to other people." (p.115). This crucial role of speech tends to justify why this research paper focuses mainly on speech rather than writing. As a matter of fact, Trudgill (1983) states that "when we speak, we cannot avoid giving our listeners clues about our origins and the sort of person we are."(p.14). According to the author, human speech is so revealing that it plays a significantly facilitative role in maintaining social interactions.

Speech is omnipresent, and we constantly engage in it either out of choice or out of necessity. It does play a crucial role in reflecting and maintaining one's status in society. Through speech, one can preserve a direct contact with his/her social surroundings, and thus engage in constructive conversations that represent a rich scope of exchanging ideas and opinions. Besides, speech is recognized to be an indispensable and a demonstrably effective means of revealing one's emotions as well as one's inner thoughts. In addition, the role of speech can be decisive in cases like a lawyer's defense at the court. All these instances seem to emphasize the crucial importance of the spoken form of language in our daily lives.

As shown by various studies (e.g. Leaper \& Ayres, 2007; Fuchs \& Toda, 2010, Chamorro-Premuzic, et al., 2015), it is commonly accepted that the biological differences between men and women are at the foundation of the observable differences between men and women, and the concomitant differences in speech and miscommunication between both sexes (e.g., Putrevu, 2001). However, this belief, though simplistic, reductionist and potentially misleading, illustrates the point that gender differences are commonly observed phenomena which are intrinsically intertwined with biological, social and cultural factors. With that being said, in this complex socio-linguistic configuration, can we aspire to a mutual communication that goes beyond all the differences?

This article aims at shedding light on the influential role that speech plays in society in general and in the Moroccan context in particular. Speech is a form of habitual action that human beings - capable of it - perform regularly, but not everyone is fully aware of the diverse functions that this form of customary behavior may entail. This study emphasizes the fact that the relationship between the individual and speech has a permanent aspect to it; that is to say, when we speak, our speech is rendered examinable and therefore becomes a reflection of a trail of evidence that reveals who we are. One's speech reflects one's communicative style that is a priori gender-marked. In this respect, being a man or a woman is not merely a biological, and by extension, a physiological question; it is rather a social image that is conveyed by the way we speak. In fact, there is enough research evidence to claim that people tend to communicate differently with members of the same gender and with the other gender. There is scarceness of research with respect to the intersection of all the aforementioned variables. Correspondingly this article seeks to raise awareness regarding the socialization processes the two sex groups have gone through which shape in substantial ways the way they speak, behave and interact among each other.

The present paper is an attempt to answer the following research questions:

1-Does the gender of the participants involved in the verbal interaction impact their styles of communication?

2-Do differences in situational and contextual variables affect the types of interaction amongst study participants? i.e., to what extent does a change in situational and contextual variables engender a change in communication styles?

These two research questions will be addressed bearing in mind the assumption that one of the ways gender identity manifests is through speech; hence, awareness of and the sense of belonging to one's gender identity may affect one's oral use of language as well as one's conversational styles in general. It has been commonly assumed that men and women speak differently, but, does this difference lead to miscommunication or communication breakdown across gender? If this is true, shall we expect men and women to communicate similarly or differently? It is probably not a matter of sameness or difference in terms of oral communication. However, it is rather a matter of each gender increasingly becoming aware of, and thus trying to identify with communication styles that are gender-specific and adopting or accommodating these styles to create successful communication.

The present work is therefore a theoretical and analytical attempt to investigate the role of gender in determining the style of communication using a convenience sample of Moroccan participants. We will also examine how the difference in situational and contextual variables affects the type of interaction among the two genders in relation to the style of communication. 


\section{The construction of gender identity}

An individual's self-conception as being male or female plays a crucial role in one's social identification. A wide range of factors, including physiological and social, contribute to the early establishment of one's gender identity. This identity is subject to a series of modifications and developments through socialization as the child gradually grows into a mature adult over time.

To illustrate this point, during the early stages of our lives as children, we start to recognize the basic concept of the self, and of our gender identity based on what others first tell us and/or expect from us. This socialization process is far more likely to induce us to consider ourselves as: "I am a boy": / ana: waladun/ or "I am a girl": / ana: bintun/ in Arabic. These two gendered statements and other self-talk or inner conversations reflect and subsequently shape one's self-image or/and social identity in a community. Freud's conception of human development investigates how gender identity develops by means of parental contribution, social reinforcement, and linguistic choices (2017). At home, the child acquires sex-appropriate language and behavior, which stand as markers of his/her identity for the rest of his/her life. Indeed, language acquisition includes the acquisition of the ability to distinguish between "he" and "she", /houwa/ and /hiya/ and to understand which belongs to either sex.

External factors such as parents' upbringing and the effect of the social environment where one is reared seem to contribute to the make-up of one's socio-cultural, linguistic, and gender identity. As a matter of fact, language stands as a crucial tool that mirrors this identity. One way this identity manifests is through the type of language one uses. The language we learn facilitates socialization and reinforces a speaker's gender identity. As the language facility develops, the characteristics identifying a speaker's identity develop and are even subject to change, and therefore, put more emphasis on the way one expresses himself/herself and how he/she is perceived by others. By the same token, these identity markers are not static; they are rather dynamic and tend to develop and change over time (i.e. age) and space (i.e. environment; culture). These constant changes may surely shape the way one would express himself/herself and the way he/she is perceived by others.

From a "gender exclusive" point of view, males and females are expected to use a set of two distinct linguistic forms. Hence, each should strictly stick to the linguistic forms that are said or/and thought to be appropriate with his/her gender. Coates (1988) cogently delineates this social pattern through the following statement: "I spoke like a woman and [my mother] yelled at me, 'Hey! You are a man, you have no foreskin, why do you talk like a woman? ...' I was ashamed."(p. 7). In this respect, gender roles are clearly preserved and perpetuated through speech. The underlying rule is that one's speech must conform to one's gender as Hudson (1980) concurs when stating that "one's speech shows who (or what) you are" (p. 49). Nevertheless, Coates (1986) is more inclined to adhere to a more liberal and tolerant vision that is "gender-preferential" rather than gender exclusive. This view supposes that instead of men and women using two exclusively distinct linguistic forms, they tend to use certain forms more frequently.

Accordingly, recognition of gender distinction determines an individual's linguistic choices and conversational manners; the way one speaks tends to be predominantly determined and shaped or at least impacted by what he/she assumes is his/her gender identity. Interestingly enough, what is noticeably remarkable is that though girls and boys are brought up in the same environmental and family conditions, they preponderantly acquire two gender-appropriate and distinct linguistic forms. With that being the case, there is practically no communication breakdown between both genders. Furthermore, this difference is regarded by society as a natural phenomenon that makes the natural difference between males and females.

As acknowledged, gender identity tends to be part and parcel of the social conventions, and gender, as such, is conceived of as "a social creation" (Poynton, 1989). Indeed, gender is a purely social and cultural construct. However, the idea of gender difference seems to be interrelated with one's conception of the self, which leads to an unconscious recognition of one's gender identification. This recognition proves to be influential with regard to topics of conversation and grammatical structures (Poynton, 1989).

Therefore, any difference in language use leads to differences in the fields of discourse, which seems to explain why certain topics are considered restricted to males (i.e., sports, money, etc) or females (i.e., cooking, make-up, etc). This line of reasoning finds true expression in the following example: "Tamara Frazer, married to former Prime Minister Malcolm Frazer, replied when asked a 'complicated economic question: 'Oh, come on, you're talking to a girl now' (National Times- Women's Role, 1983, p.3, cited in Poynton 1989).

What follows from this is that we are confronted with a social stratification where a belief that topics are subject to gender-specific selection is already a recognized convention. This convention seems to emphasize the idea of gender difference and the different characteristics that identify any cross-gender interaction. If men and women tend to prefer different topics for discussion, then we should expect that their communication styles would differ according to the nature of the chosen topic. 


\section{Gender: dominance or difference?}

\subsection{Dominance approach}

Romaine's (1994) statement that "women's speech has just been ignored" is worth to be considered here. This statement stresses Romaine's contention that women have often been overlooked, if not to say utterly marginalized, from the linguistic and the sociolinguistic research during the first part of the twentieth century. This viewpoint emphasizes the conspicuous presence of manly speech and social domination (Benattabou, 2020, 2021a). However, nowadays the question of how to conceptualize the male/female relationship, whether it is one of domination or differentiation has been subject to highly controversial and sizeable debates. It appears that men and women tend to develop different speech habits. In this sense, research endeavors must be geared to first understand the nature of this difference, and then find ways to account for it in an objective and unbiased manner.

Traditionally, men have been seen for a long time as synonymous with power and social defiance as well as dominance over the other gender. This widely acknowledged belief denotes that "to be a woman is to be subordinate" Romaine (1994). In this respect, Lakoff (1973) argues that this kind of "women's language" that mirrors an inherent allusion towards inferiority and subordination results from the socializing factor that reflects women's inferior position. Lakoff's view emphasizes the effect of a patriarchal society on the personality formation of women. He claims that women are brought up to attribute authority and power to masculinity. In response to that, they should strictly avoid any qualities that may associate them with the other sex. Throughout history, women have oftentimes been taught to display the feminine qualities of weakness, passivity and deference to men (Benattabou, 2020, 2021b). Accordingly, women are socially expected to develop language styles that reflect a psychological state of insecurity and powerlessness, which can easily be misinterpreted for over-politeness. In this vein, Nadif (2006) underlined significant differences in the distribution of terms of politeness across gender in the Moroccan context.

Still, this dominance approach reflecting a single voiced discourse, the male's, has taken another dimension, which is asserted by O'barrand Atkins (1980) pointing out that "Lakoff's Women's Language was wrongly named; it was not a gender marker but a status marker." This shows that men's gender dominance that is reflected through linguistic behavior was rather perceived to be status dominance. Accordingly, society became stratified into two layers of unequal statuses, dominant and subordinate, which gave birth to what can be termed a social culture of dominance. Here is an example that gives form to this phenomenon by DeFrancisco (1991, p.413):

I want him to tell me what he's thinking, what he's feeling ... about a month ago I said 'Hal, talk to me, just don't sit there like a bump on a log. Talk to me ...'He'll, when we're arguing mostly, I'll say, 'just explain to me now, what are you saying, what is it?' And he won't. He takes it as an insult I guess that I don't understand what he's saying and he won't explain ...'(A 21-year-old Hispanic woman describes communication with her husband.

Mixed-gender communication as a natural phenomenon in a society where both genders have to co-exist has gained much attention among many sociolinguists and feminist researchers (Khoumich and Benattabou, 2020). The above-cited quotation illustrates a conversational situation where communication hardly takes place. The woman speaks and asks the man to converse with her, but though silent, the man is apparently dominating the conversational situation. Silence here is power and dominance, and speech (the woman's speech) is a reaction to the undesirable effect of this power. The absence of mutual desire to communicate and the non-responsive attitude of the husband, though it appears to be personal, may reflect a whole underlying social paradigm that spotlights the unequal distribution of power across gender.

What is noticeable is that though the woman may be perceived as "talkative" she is still unable to dominate the conversation; this inability is embodied through the absence of any feedback from her husband. It can be said that the differences in speech and approach to conversational interaction between men and women are thought to be a direct result of status differential social stratification. This line of argumentation sees language as a more powerful socializing agent whereby a woman's subordinate status in society is maintained and reinforced. (Nadif, 2006)

\subsection{Difference approach}

As its name suggests, this approach endorses the prevalence of the culture of difference rather than dominance. Essentially, the underlying proposition is that men and women, when engaged in a conversation, make use of different rules and assumptions for managing conversational interaction in mixed gendered-communication. To put it differently,

Difference is simply assumed, with no awareness of the extent to which adult behavior creates that difference. If it were simply a matter of difference, however, where men and women have their own spheres of activity 
with rights and status and a complete range of possibilities for achievement within those spheres, then one might feel less concerned. (Poynton, 1989)

Gender difference is an existing social phenomenon that trespasses the narrow private spheres to a wider social dimension. When we speak about difference, merely describing it is not an end in itself but, as alluded to before, it has the potential to help in diagnosing reasons for communication breakdowns and remedial procedures to eliminate those communication handicaps. In this regard, problems are thought to occur because different communication styles result in different interpretations of meaning and intention.

In conformance with what is previously stated, what we shall do is first to appreciate the differences, and then accept them as part of the natural and cultural construction of society. That being said, the question that arises here is, "does cross gender communication exist?" If yes "Can we discard it from our life?" If no, "How does communication take place in mixed gendered conversations?" The answers to these questions and others will be investigated in the upcoming few pages.

\subsection{Cross-gender communication}

Accepting the fact that men and women have different approaches to communication is necessary for any understanding of what these differences are, and how they come into being along with their effect on each other's communicating styles.

Both dominance and difference approaches consider power as a vital factor in cross-gendered communication. On this subject, Fishman (1983) considers that differences between men and women are a direct result of power imbalances in communication. Joining Lakoff (1973), she believes that the power that is reflected in mixed conversations springs from socialized genderappropriate behavior. In this sense, Fishman's viewpoint is an indirect assertion that neither men nor women are to blame because of miscommunication between both genders.

Coates (1998) gave a true-to-life image of the lack of communication between a husband and a wife.In real life conversations at home, many women are hurt when their husbands do not talk to them at home. They complain that their husbands are usually talkative with their colleagues, friends or relatives but usually keep silent at home. However, what we should note here is "do men and women consider this undesirable situation from the same angle?" Are men also disappointed?" If we consider these questions, then, this situation may be attributed to social rather than personal factors. Perhaps, women seem to be more used to verbalizing their feelings with friends and relatives while men are far more likely to keep their own feelings and thoughts to themselves.

Tannen (2001) argues that men are more talkative than women in the workplace. Generally, men are the "talkers" in the public places while women are the "talkers" in the private settings. Tannen (2001) explains this situation contending that while men consider that talk is information and competition, they tend to be silent at home because they see no need to use language in a competitive manner with someone with whom they feel comfortable. This explanation may help in overcoming mutual miscommunication between both genders; a miscommunication that is a result of lack of understanding rather than irrational underestimation of the other gender.

\subsection{Communication styles and strategies: making the difference}

Computer mediated communication (henceforth, CMC) is a form of communication which involves members of the same sex, different sexes, same age and different ages, same culture and different cultures. Surely, this means of communication is widely prevalent nowadays, but if we believe in gender difference, and if the theory of dominance reflects some degree the potential problems that may hinder communication between both sexes, then this kind of communication negates the face-to-face factor from cross-gender interaction. In addition, other means of communication as telephones and mobile phones do nullify this factor. But, direct verbal contact continues to exist. In a similar manner, other means that are more traditional as letters are still widely used. According to We (1993), CMC has the ability to "help people, no matter what their gender, race, or physical appearance, communicate with each other with fewer prejudices and misunderstandings than any other medium in existence". Computer mediated communication may foster communication between men and women thanks to its ability to withhold or camouflage gender stereotypes and prejudices.

Similarly, internet cafés are now more than entertainment; they have become an area that shows the influence of technology on human communication. The internet has become a means of socialization for men and women. Incidentally, a field study carried out by We (1993) examines man's opinion towards mixed gendered CMC. The findings revealed that "women get heard more because they can finish a thought without being interrupted". Indeed, We (1993) goes further to illustrate that men are used to interrupt women in cross-gender interaction; a habit that impedes women's self-expression. 
Additionally, from a difference point of view, if men and women are two different social persons, then it is understandably natural that communication styles and strategies differ between both sexes. Along the same line of reasoning, Maltz and Borker (1982) argue that men and women do not play the same role in cross-sex interaction. They then give a view of the different aspects of the male and female contribution in mixed communicative situations. Fishman (1978, p. 400) comments that "at times I felt that all women did was ask questions, and Hirschman (1973:10) notes that "several of the female-male conversations fell into a questionanswer pattern with females asking the males questions." (Maltz and Borker 1982, quoted in Coates (1998, p. 418)

Maltz and Borker note that the tendency of asking questions illustrates the woman's role in doing the "shiftwork" in male-female conversations, which is an attempt to keep contact and preserve social interaction with the other speaker. Another characteristic of women's speech is that they usually resort to "silent protest" as a means to show their dissatisfaction after being interrupted or after receiving a delayed response. Additionally, women frequently use the pronouns "you" and "we" as a means to recognize the presence of the other interlocutor.

As for men, Maltz and Borker quote Zimmerman and West (1975) pointing out that women complain that men unceasingly interrupt their speech. In this connection, Maltz and Borker claim that men frequently show a tendency to challenge their interlocutor's speech (women's speech) while they tend to ignore the latter's comments by not responding, or by displaying unenthusiastic response. Furthermore, Zimmerman and West (1975) explain that men use techniques like topic development and tend to introduce a new topic for discussion to control the conversation. Ultimately, Fishman (1978) notes that men have the tendency to use more direct declarations and opinions than women do in cross-gender conversations.

\subsection{Significance of cross-gender interaction}

Explanations for the different conversational aspects of men's and women's speech are based on the notion of gender power and gendered hegemony in patriarchal societies. Zimmerman and West (1975) note that "men's dominance in conversation parallels their dominance in society" and that "men enjoy power in society and also in conversation" (cited in Coates 1998, p. 419). On a par with this, Fishman (1978) stipulates that:

Norms of appropriate behavior for women and men serve to give power and interactional control to men while keeping it from women. To be acceptable as women, women cannot exert control and must actually support men in their control. (Coates 1998, p.419)

The two viewpoints seem to emphasize the role of the socializing process in cross-gender interactions, which is consonant with Lakoff's (1973) concept of socialized identity. Men's dominance in communication seems to be part of the social conventions that assign different roles to each sex. These roles are woven into and intertwined with one's gender identity. Conversely, Coates (1998) presents a different vision based on psychological, cultural and power differentials. She notes that differences may be attributable to individual differences in conceptualizing gender roles and sociolinguistic subcultures.

We argue that American men and women come from different sociolinguistic subcultures, having learned to do different things with words in a conversation, so that when they attempt to carry on conversations with one another, even if both parties are attempting to treat one another as equals, cultural miscommunication results. (1998:p.420)

According to Coates, the impact of difference is beyond the social and the individual observable behavior; it is rather a cultural construct which elicits results directly from different social habits and norms that are gender-specific. The problem is thus revealed to be the outcome of misunderstanding rather than miscommunication. The latter is a byproduct of the former.

\section{Methodology}

\subsection{Research questions}

The present paper is an attempt to answer the following research questions:

1-Does the gender of the participants involved in the verbal interaction have an impact on the styles of communication?

2-Do differences in situational and contextual variables affect the types of interaction amongst study participants? i.e., to what extent does a change in situational and contextual variables engender a change in communication styles?

\subsubsection{Sample description}

Using a homogenous convenience sample of Moroccan participants chosen to serve the purposes of this study in the Moroccan context, 20 male participants and 20 female participants were recorded during their conversations which took place in different 
contexts: at home, at work and in the street. In addition, these participants were interviewed because the interviews allowed interlocutors to express their attitudes towards communication in general and towards the other sex in particular.

\section{2. Data collection procedure}

This study is also an attempt to explore the extent to which changing the setting engenders a change in communicational styles throughout the data analysis section. The overview of the literature related to the construct of gender identity, the social perception of gender difference and cross-gender communication is hoped to have provided a substantial idea of the socio-linguistic research relevant to mixed-gender interaction. Along with that, the field of study of men's and women's communicating styles can provide considerable implications on how the difference in communication styles between men and women, girls and boys come into being along with how people are able to communicate with members of their opposite gender.

Recording everyday speech and interviews with male and female respondents represents the methodological device of data collection in this research paper. In this regard, emphasis has been placed upon both single and mixed-gender conversations in addition to enquiries about each sex's perceptions of one's communication styles, and the other's linguistic behavior in crossgender communication. Indeed, several are the communicational aspects that attract one's attention in any conversation, the most important of which are male interruption and conversation dominance, and women's use of tag questions, use of voice pitch, frequency and length of turn-taking.

The setting of the conversation is important. The recorded conversations took place in different contexts: at home, at work and in the street. The interviews allowed interlocutors to express their attitudes towards communication in general and towards the other sex in particular. The interviews also demonstrated the change of social and cultural perceptions among people. This could be seen through the direct statements of the respondents.

In fact, in order to understand if men and women approach communication similarly or differently, it is necessary to have a closer scrutiny of men's and women's assured styles of language use while they are involved in real communication situations. Failing to see style differences for what they are may at times be conducive to draw inaccurate, unfair and misleading conclusions.

\subsection{Data analysis}

Table 1. Male respondents' distribution by age

\begin{tabular}{|c|c|c|c|c|c|c|}
\hline Age & & $20-25$ & $26-30$ & $31-35$ & Over 35 & Total \\
\hline $\begin{array}{l}\text { Number of } \\
\text { respondents }\end{array}$ & female & 4 & 6 & 6 & 4 & 20 \\
\hline Percentage & & $20 \%$ & $30 \%$ & $30 \%$ & $20 \%$ & $100 \%$ \\
\hline
\end{tabular}

Table 2. Female respondents' distribution by age

\begin{tabular}{|c|c|c|c|c|c|c|}
\hline Age & & $20-25$ & $26-30$ & $31-35$ & Over 35 & Total \\
\hline $\begin{array}{l}\text { Number of } \\
\text { respondents }\end{array}$ & male & 4 & 6 & 6 & 4 & 20 \\
\hline Percentage & & $20 \%$ & $30 \%$ & $30 \%$ & $20 \%$ & $100 \%$ \\
\hline
\end{tabular}


As the figures in Table 1 and Table 2 show, the 40 male and female interviewees belong to various age groups, which is believed to help in demonstrating whether the age factor influences communicative behavior and beliefs about gender-specific speech. Furthermore, the figures indicate that the elicited views are not restricted to a given age group.

Additionally, all the respondents have received a more or less considerable amount of education. All of them are workingmen and workingwomen except two females who are stay-at-home moms. Three females and five males are married while the other interviewees are single. The age of the students in the observed classes ranges between 16 and 19 years old.

The settings of the conversations and communicative interactions where the data has been elicited involved both single and mixed genders as well as different contexts and situations (i.e., at home, workplace and the classroom).

\section{3. 2. At home}

\subsubsection{A husband and wife: a state of miscommunication}

According to We (1993, p. 90), "communication between women and men has always been problematic, to say the least." However, home is the main family gathering place. It is the setting shared by parents and children in a typical family. Therefore, the family members are likely to be engaged in everyday communication in an authentic and spontaneous manner, which indicates that cross-gender conversations are more likely to occur at home. With this, it becomes easier to identify gender styles in conversation along with gendered speech characteristics and their effect on the conversation as Tannen (2003) explains:

The family is a microcosm of gender relations. In order to understand talk in the family, we have to first understand gender patterns in talk. And the family is the training ground on which we learn to inhabit, express, and manipulate the patterns of behavior, the ways of talking that are associated with gender. (p.45)

Coates (1996) points out the importance of place of talk in the women's friendships. She notes: "what do you do with your women friends? Jo said, simply, 'Talk'; Bea said, 'We talk', and Val said, more emphatically, 'We talk', primarily we talk, 'we never stop talking' (p.44). Similarly, a woman answering the same question said:

\section{Situation 1:}

'Min tabi?tlhal, hnal?yalat ma tantlaqawfeddarillabachnhadrou ala koulhaja we ay haja'

[Of course, we, women meet at home primarily to talk about anything and everything]

\section{Situation 2:}

Another woman noted:

'Ana baadailamatkalamtchfdarraninmrad. Walakinrajlitayji mal khadma aw lqahwamabariwalouillayatfarajfetalfaza aw yaqra journal'

[As for me, if I do not speak at home, I will surely get sick. But, my husband comes from his work or café only to watch television or read newspapers]

The first statement reflects women's desire to talk at home. The second statement reveals almost the same idea delineating women's strong wish to have someone to talk to. In the second extract, there is an allusion to the fact that the woman's will to talk as a means of communication and self-expression has been aborted by man's indifference. Such a finding displaying man's lack of responsiveness is in concordance with De Francisco's (1991) aforementioned quote.

\subsubsection{The home is the place of talk-communication}

The following table illustrates the respondents' reaction to the question "do you think that the home is the place to talk or to take a rest?" 
Table 3. Female responses to the question of how home is viewed

\begin{tabular}{|c|c|c|c|}
\hline Choice & $\begin{array}{l}\text { The home is the place to } \\
\text { talk in }\end{array}$ & $\begin{array}{l}\text { The home is the place to } \\
\text { rest in }\end{array}$ & Total \\
\hline Females & 15 & 5 & 20 \\
\hline Percentage & $75 \%$ & $25 \%$ & $100 \%$ \\
\hline
\end{tabular}

Table 4.Male responses to the question of how home is viewed

\begin{tabular}{lccc}
\hline Choice & $\begin{array}{l}\text { The home is the place to } \\
\text { talk in }\end{array}$ & $\begin{array}{c}\text { The home is the place } \\
\text { to rest in }\end{array}$ & Total \\
\hline Males & 8 & 12 & 20 \\
Percentage & $40 \%$ & $60 \%$ & $100 \%$ \\
\hline
\end{tabular}

The figures in Table 3 show that $75 \%$ think that the home is primarily a place for discussion. They added that home is where they feel at ease to talk either with family members or female friends. Some added that at home, they can speak as loud as they want and about any topic they like. However, this is not the case for men, $60 \%$ of whom consider the home as a place to have some rest (Table 4). Men's liability to see the home context as an ideal place for rest and relaxation implies less talking and less conversing. Surprisingly enough, it has been observed that $40 \%$ among men consider the home talk as the most effective talk where they may cooperatively converse and chat with their family members.

Women have constantly been considered as a talkative sex (Coates, 1996). However, talkative is not always synonymous with futility. Let us consider the following dialogue:

Wife: [Addressing her husband who has just come home]

Khalid, jitimelkhadma?

(Khalid, are you back from work?)

Husband: Yeah

(yes)

Wife: Khalid, kedouwezetinhar? Wachkam'alti I...../)

(Khalid, how was your day? Did you finish the ..../)

Husband: Oh! Rifelkhadma we hriqrass. Achnoutaibti na had nhar.

(Oh! Just at work and its trouble. What did you cook for us today?)

Wife: Qouli, yak I oumourmezianafelkhadma?

(Tell me, is everything ok at work?)

\#

Husband: Chwia. 
(It's ok)

Wife: Wmalekmqalaq?

(Why are you nervous?)

Husband: La walouRibaRinartahchwia.

(No, nothing. I just want to have some rest)

\#

Wife: Wakha, yallahntghdaw

(Ok. Let's have lunch)

Note: (.../) indicates interruption, and (\#) indicates a pause of a few seconds.

Through the dialogue, it is remarkable that in terms of turns, the wife takes one turn more than man. However, this does not indicate domination but a will to maintain conversation and express concern for the other. Further, we can notice that the turntaking means usually a question that signals the next speaker's turn. However, the symmetry of the turn-taking system is violated when the husband abruptly intervenes to answer the question of the first part of the turn. Indeed, the husband - the interrupter succeeds in preventing his wife from finishing her turn. This may be the only interruption in the dialogue, but it is a successful and non-supportive one since the interrupter manages to take the floor, which indicates power and even unwillingness to pursue the conversation.

This imbalanced pattern of male-female interaction where men are observed to interrupt women far more often than women do is consonant with the findings of a wide range of research studies (Eakins \& Eakins, 1976, McMillan et al., 1977; Khoumich and Benattabou, 2020).

Further, the dialogue shows that the husband resorts to minimal responses twice (Yeah, ok), whereas the wife uses none of them. Likewise, the observation of male-female exchanges revealed that the women's use of minimal answers is rare, and when they were used, it was to indicate active listenership to the speaker. However, men tended to use minimal responses as a signal of nonsupportive attitude and unwillingness to pursue the conversation. The latter case sounds compatible with the situation in the previous dialogue.

Moreover, it was noticed that that conversational pauses are more common with men's conversations than in women's. On the other hand, in most females' conversations, conversational pauses were present only at the beginning of the conversation or when a new topic is introduced. But, as women were engaged in the conversation mainly a debate-oriented one, there was no resorting to pauses and there was a strong competition to take the following turn.

The following section will focus on cross-gender interaction at the workplace where mixed-gender communication occurs.

\subsubsection{At work}

This section investigates the position of women in the work place along with the major characteristics of male-female interaction. The purpose is to demonstrate how the conventionally established construct of gender difference and/or dominance is reflected in work relationships, practices and in almost all verbal interactions.

\subsubsection{Talking as gendered experience at the workplace}

The way we communicate with others is revealed through our everyday speech interactions. More specifically, the language patterns opted for in order to meet certain communicative needs and achieve certain purposes tend to reflect a large extent people's gender identity as males or females. As a matter of fact, talking about the workplace evokes how people avail themselves of language as a medium to make or express orders, commands, promotions, raises and recognition. This section attempts to investigate how gendered language patterns operate in the workplace environment. Men and women are said to speak differently; this is especially so in terms of the ways they share information, listen to their interlocutors, make decisions, and above all handle disagreements and resolve conflicts. In this regard, the way an individual speaker acts may highlight the differences in mixedgender communication styles. 
In the past, societies were such that the working female was rather an exception, not a rule. Women were seen and expected to fulfill their domestic duties. In parallel, the female discourse was supposed to be limited to the household-related affairs and could very rarely extend to outside political, economic or cultural issues, particularly in male-dominated settings.

Nowadays, one can hardly find out a single-sex domain or a workplace exclusively for men or women since they both work side by side in almost every field. This radical cultural evolution has made daily interaction between men and women inevitable. However, working together does in no way mean that the problem is solved as communication involves individual attitudes, convictions and cultural awareness. Therefore, any change regarding the general atmosphere in the workplace should by implication incorporate a change at the level of all of these components.

\subsubsection{Cross-gender interaction: at the workplace}

Knowledge or possession of information is an integral part of the everyday experience of every functional human being in society. In relation to our study, $75 \%$ of the female interviewees claimed that for them information is usually not originally theirs, and that they feel at ease sharing it with others. This may perhaps be interpreted as one of the reasons why females are described as a talkative sex. In this vein, it is worth noting that Coates (1996) asserts that people believe that women never stop talking. For females, sharing information is an important instrument to build social rapport and maintain communication with others. However, the same female participants claimed that they feel more at ease when they speak with females than with males. They think that when males share information, it is only to show their expertise. Tannen (2003), sharing the same viewpoint, makes a pertinent distinction between men's "report talk" and women's "rapport talk", which indicates men's tendency to inform and explain, and the females' willingness to build social ties by sharing information.

\subsubsection{A case-study analysis: at the workplace}

This case-study involves subjects working as teachers and administrative staff members in lbno Battouta school in Fez. The study was carried out with the participation of 62 teachers where 41 were female while 21 were male, in addition to 8 administrative workers, all of whom are male.

Table 5.Gender distribution of participants (Teachers and administrators)

\begin{tabular}{cccc}
\hline Participants & Male & Female & Total \\
\hline Teachers & 21 & 41 & 62 \\
Administrators & 0 & 8 & 8 \\
\hline
\end{tabular}

It was noticeable right from the first day of working in Ibno Battouta school that teachers were exclusively female. This was not due to an internal administrative regulation or decision; it simply happened to be a spontaneously and authentically gendermarked environment.

\subsubsection{Cross-gender communication: females' voices}

The first question we raised took place in the staff room and was therefore, addressed to female teachers. "Why are men absent in this room?" It was noticed that the question was not that surprising to them, and we immediately started recording a substantial amount of responses to the question. Whenever a female teacher spoke, the others seemed to agree with her. Among the assumptions embedded in their responses were that males are absent because most of them are smokers, so they prefer to stay outside. Others thought that some males are too shy to share the room with all those female teachers. However, $96 \%$ of females assumed that women's conversational topics differ from the males', making it preferable for males to stay outside the room to feel at ease while talking about what they called "manly topics". For females, manly topics include mainly sports and politics.

Furthermore, this line of reasoning seems to resonate well with Poynton's (1989) findings that there is an already established convention shaping what males and females actually think about the selection of some gender-specific subjects. It can then be said that female teachers think that personal problems, such as pregnancy, cooking, home problems, and private life are purely female topics. However, they asserted that there are topics that both men and women frequently talk about such as work difficulties, raises, and the costs of living. 17 out of 25 female interviewees in the room stated that apart from work issues, they prefer to converse with women. However, we have come across some statements, such as the following:

\section{Situation 3:}

W: Ana chakhciyantanfddalnethaddethmaamrabhali, m?ahayemkallinehderaalaloumourkhassadiali, yamkellinehderkimabghit. 
[Personally, I prefer to talk with a woman like me. With her, I can talk about my private issues, I can talk as I like]

\section{Situation 4:}

W: Ana tanfeddelnatkallemmaarjal, liana hadra diallaayalatghalibantatkoun ntafiha.

[l prefer to talk to men because women's talk is usually about futilities]

\section{Situation 5:}

W: Ahyananlhedramaarjaltatfid, taykounaandhoumttajaribkthar mina.

[Sometimes, talking with men is beneficial; men have more experience than we do]

\section{Situation 6:}

W: Ana tan feddelnehdermaanissaawalakinmachi ay nissaa. Nissaalilhadramaahoummoujdia

[l prefer to talk to women, but not any women; just the women with whom talking is beneficial]

What follows from the analysis of these conversational extracts is that there are several viewpoints that are somewhat paradoxical. Indeed, communication between males and females is a fundamental human need. Through the statements, we can deduce that the general belief is that communication sounds better in single-sex conversations, as indicated in situation (3), for participants enjoy more comfort and freedom of speech. However, there is a viewpoint which may be qualified as selective; it is for single-sex communication on the condition that the topics and the interlocutors are interesting enough as in situation (6). On the other hand, the opposite view that is expressed in situation (5) indicates a preference for mixed-gendered communication claiming that men have more experience than women. This very statement raised heated debate among teachers, and we decided to shift to another question when we realized that the conversation started taking a feminist dimension.

Another more surprising standpoint is the one expressed in situation (4) where the female respondent states that talking to women is seldom fruitful. Consequently, she thinks that with men it would be different. In this particular case, mixed-gender communication is not a result of personal will and conviction, but of dissatisfaction and need for an alternative.

\subsubsection{Cross-gender communication: males' voices}

This part of the case-study analysis is devoted to the male teachers' views about the reasons why men were absent from the staff room and cross-gendered communication. First, the issue was raised to male participants, and a similar discussion followed based on the same questions that were addressed to female teachers.

The discussion of why male teachers preferred to stay outside the staff room away from women revealed that male teachers constitute a tiny minority and therefore tended to have none to converse with in the first place. The other question was related to male teachers' tendency to shun from verbally interacting with their female counterparts. All the answers seem to boil down to the idea that each gender group happens to have their own gender-specific topics and issues they like to resolve within their shared gender identity group. More precisely, women seem more comfortable talking about fashion, clothes, or cooking. As a matter of fact, maximizing interaction between men and women will require both parties to attend to the topics or issues that are appealing and worthwhile to both sex groups

Equally important, it turns out that sport which is commonly considered as a purely masculine topic was also an appealing area of interest for female teachers as well. De facto, sports in general and football in particular, were found to be the subject matter of mixed conversations involving male and female teachers.

As it is clearly noticeable in situation (5), a woman participant in the study underlined that the reason why she prefers to converse with men rather than women is that men know more, and they are more experienced than women. However, another male teacher does not seem to share the same viewpoint. The question was: "Do you think that a man knows more than a woman? The answer was as follows:

\section{Situation 7:}

Mayemkenchnqoulou bi annarrajoulaandouilmam aw maaarifaktarmina Imara". liannalyawmlmara" tatmchi I medrassa" bhalbhalrrajoul, tataamelfelidarat, tateqraljaraid. Wahattarabbatlbayttatkountahtambichouounihadakhilalbayt. 
[We cannot say that a man is more knowledgeable than a woman because nowadays, the woman goes to school side by side with the man; they work in the administrative departments, and they read newspapers. Even housewives have considerable knowledge of the house and its demands].

Generally speaking, it could be deduced that males do not demonstrate any superiority vis-à-vis females. Neither do they express any reluctance or refusal to get engaged in mixed-gendered conversations. However, reality does not reflect these beliefs. It appears that variation in terms of choices of topics between men and women persists, at least in so far as the results of our investigation revealed so far.

\subsubsection{In the classroom}

The classroom is yet another place where cross-sex interaction is bound to occur. The co-presence of boys and girls in the same classroom makes the participants and classroom experience a gender sensitive one.

In the three classrooms we observed, the average number of students was 35 students per class. In every classroom, girls represented a majority of $62 \%$. The turn-taking system, the amount of speech, and classroom achievement vis-à-vis oral participation represented the focal points of our observation.

Language learning and acquisition take place through communication and verbal interaction not only among teachers and learners but also, to a large extent, among learners themselves (also known as peer-learning). However, turn-taking proves to be a highly essential component for effective and successful communication. Classroom observation conducted for the current study reveals that teachers usually do most of the talking and tend to control turn delivery in the classroom as well. In easy terms, teachers manage turn-taking in the classroom. Thus, out of 25 turns taken by different students in a one-hour lesson, the teacher selected a speaker 19 times. However, the selected speaker is usually a volunteer; he/she raises his/her hand to signal the willingness to speak.

Surprisingly enough, male students were observed to take more turns than their female counterparts. The teachers ascribe this phenomenon to shyness and sometimes inhibition on the part of females. In this respect, we observed that, in general, male students dominate classroom oral participation. However, the teachers asserted that when it comes to classroom written exams, girls tend to score higher than boys, and usually the top marks are allotted to them.

Additionally, at more advanced levels where the teacher usually introduces some debatable topics for discussion and each student or group of students should defend their standpoint, it has been noticed that the number of the turn-takings was higher particularly when the debate was between a female group and a male group. The number of turns that each group took in these mixed discussions was not that different.

From what has been observed, the classroom can, to a great extent, offer a valuable opportunity for cross-gender interaction. This means that classroom activities that encourage group work, mainly groups including males and females can reliably enhance communication and mutual understanding between both sexes. The main findings of the present paper indicate that though communication breakdown might all be a source of disappointment, it remains a common phenomenon in social interactions. Thereof, overcoming difficulties in maintaining effective communication between members of different genders is dependent on the interlocutors' belief that accepting difference in language and communication styles can make cross-gender communication a worthwhile social experience.

\section{Conclusion}

This research paper hopes to have analyzed the influential role of speech, gender and identity, dominance/difference, and crossgender communication in the Moroccan context. Language lies at the core of any form of human communication. As part of a sophisticated thought process, we could hypothetically assert that if there is one complex skill without which man as a species can hardly thrive in the social realm, it is language. This is because conceiving of an alternative social and cultural order would be nothing less of a considerable cognitive undertaking for the human imagination. From a sociolinguistics perspective, each individual speaker's linguistic choices, different roles he or she plays, and the plethora of situations where the speech takes place to serve as markers reflecting one's identity and communication styles.

The findings of this research paper lend more credence to the premise that males and females, in the course of group relationships, tend to make different linguistic selections in terms of their communicative behavior. However, since mixed conversations are fundamental characteristics of our social and cultural lives, we can no longer be contented with pointing out the differences; we are inspired and encouraged to attempt to go beyond the differences between the two sex groups by maximizing genuine understanding and establishing a culture where such core human values as tolerance and acceptance of the other are given more attention than heretofore. 
In conclusion, gender-based differences in conversational styles are facts in many different cultures with varying degrees of strength and expression. At this point, sociolinguistics studies, through examination of both the difference and the dominance theories, can facilitate the process of bridging the communication gap between men and women. It is only by doing so that we may reasonably admit that we have succeeded in placing the wheel of cooperation, collaboration and mutual understanding among the two sex groups on the right track.

Funding: This research received no external funding.

Conflicts of Interest: The authors declare no conflict of interest.

Acknowledgement: We would like to thank all the participants in the study.

\begin{abstract}
About Authors
1-Ismail Benfilali is a Ph D holder and Assistant Professor from the English Department of Sidi Mohamed Ben Abdellah University, Fez-Sais, Morocco. His main research interests are applied linguistics, gender issues and sociolinguistics. He has published a number of articles in such research areas as Applied Linguistics, gender studies, among other research interests.
\end{abstract}

2-Bendaoud Nadif is a PhD candidate at the Department of English, Faculty of Arts and Humanities, Meknes, Morocco. His research interests revolve around such areas as Applied Linguistics, EFL learning and teaching, and Good Language Learner Research. He has facilitated many webinars both nationally and internationally. He has published a number of articles in such research areas as Applied Linguistics, gender studies, cultural studies, among other research arenas.

3-BrahimKhartite is a Ph D holder from the Faculty of Educational Sciences Rabat Morocco. He is currently an Assistant Professor of Engineering English at ENSAM, Meknes Moulay Ismail University, Morocco. He participated in UME programs in Boston USA (2005) and Seville Spain (2006). His main educational concerns and interests include, among others, schema theory and reading comprehension, teacher training and continuous professional development.

4- Driss Benattabou is a professor of English at the Department of English, Faculty of Arts and Humanities, Meknes, Morocco. He holds a Ph D from Moulay Ismail University, Meknes, Morocco. He has published a number of articles in such research areas as Applied Linguistics, Gender in Education, Critical Discourse Analysis and Visual semiotics.

5- Abdelouahed Bouih is Ph D. Candidate, English Department, Moulay Ismail University, Meknes, Morocco. He has published a number of articles in such research areas as Applied Linguistics, gender studies, among other research interests.

\title{
References
}

[1] Benattabou, D. (2020). Gender imbalances in the visual discourse of Moroccan EFL textbooks: A critical image analysis. Journal of Translation and Language Studies, 1(1), 1-25.

[2] Benattabou, D. (2021a). Gendered hegemony in the visual discourse of Moroccan EFL textbooks: A quantitative content analysis. International Journal of Linguistics and Translation Studies, 2(1),14-61.

[3] Benattabou, D. (2021b). The visual 'Masculinization' of Moroccan EFL textbooks: A social semiotic analysis. Feminist Research, 5(1), 1-19.

[4] Coates, J. (1986). Women, men, and language: A sociolinguistic account of sex differences in language. Longman.

[5] Coates, J. (1988). Women's Speech, Women's Strength? Paper presented at the Sociolinguistics Symposium, York, England.

[6] Coates,J. (1996). We never stop talking: talk and women's friendship in Women Talk. Blackwell Oxford.

[7] Coates, J. (1998). 'Thank God I'm a Woman': The Construction of Differing Femininities. The Feminist Critique of Language: A Reader. 2nd. ed.. Routledge, 297-320.

[8] DeFrancisco, V. L. (1991). The sounds of silence: How men silence women in marital relations. Discourse\& Society, 2(4), 413-423.

[9] Eakins, B., \&Eakins, G. (1976). Verbal turn-taking and exchanges in faculty dialogue. The sociology of the languages of American women, 5362.

[10] Fishman, P. M. (1978). Interaction: The workwomen do. Social Problems, 25(4), 397-406

[11] Fishman, P. (1983). Interaction: the work women do. In Thorne, B., \& K., Cheris (eds) Language, Gender and Society pp. 89-102. Newbury House.

[12] Freud, S. (2017). Three essays on the theory of sexuality: The 1905 edition. Verso Books.

[13] Fuchs, S., \& Toda, M. (2010). Do differences in male versus female/s/reflect biological or sociophonetic factors. Turbulent sounds: An interdisciplinary guide, 21, 281-302.

[14] Hudson, R.A., (1980) Sociolinguistics. Cambridge University Press.

[15] Khoumich, A.\& Benattabou, D. (2020). Students' perceptions of teachers' gender-biased treatments in the classroom context. International Journal of Linguistics, Literature and Translation. Volume 3, Issue 10, October 2020, pages 1-14.

[16] Lakoff, R. (1973). Language and woman's place. Language in society, 2(1), 45-79.

[17] Leaper, C., \&Ayres, M. M. (2007). A meta-analytic review of gender variations in adults' language use: Talkativeness, affiliative speech, and assertive speech. Personality and Social Psychology Review, 11(4), 328-363.

[18] Maltz, D., \& Borker, R. (1982). A cultural approach to male-female misunderstanding. Language and social identity, 198-215.

[19] McMillan, J. R., Clifton, A. K., McGrath, D., \& Gale, W. S. (1977). Women's language: Uncertainty or interpersonal sensitivity and emotionality? Sex Roles, 3(6), 545-559. 
[20] Nadif, B. (2006). The distribution of politeness terms in Moroccan female speech: Beni Mellal as a case study. (Unpublished D.E.S.A. Dissertation, Faculty of Arts, Fez).

[21] O'Barr, W.M. and Atkins, B.K. (1980). "Women's language" or "powerless language"? In R. Borker, N. Furman , and S. McConnell-Ginet (eds.), Women and Language in Literature and Society (New York), pp. 93-110

[22] Putrevu, S. (2001). Exploring the origins and information processing differences between men and women: Implications for advertisers. Academy of marketing science review, 10(1), 1-14.

[23] Poynton, C. (1989). Language and Gender: Making the Difference. Oxford University Press.

[24] Romaine, S. (1994). Language and gender in Introduction to Sociolinguistics. Blackwell.

[25] Tannen, D. (2001). Talking from 9 to 5: Women and men at work. Harper.

[26] Tannen, D. (2003). Communication Matters: He Said/She Said: Women, Men and Language Recorded Books, LLC.

[27] Trudgill, P. (1983). Sociolinguistics: An Introduction to Language and Society, Penguin Books, England

[28] We, G. (1993). Cross-gender communication in cyberspace. The Arachnet Journal on Virtual Culture, 2(3).

[29] Williams, M. \& Burden, R. L. (1997). Psychology for Language Teachers: A Social Constructivist Approach. Cambridge University Press.

[30] Zimmerman, D. H., and West, C., (1975) Sex roles, interruptions and silences in conversation Language and sex: Difference and dominance. pp: 105- 129. Stanford University Press. 